\title{
Aspectos da gestão de pessoas e do capital humano evidenciados no relato integrado
}

Partindo da premissa de que o capital humano é crucial para o desenvolvimento de uma organização, sua evidenciação é relevante para avaliar e compreender a criação de valor em termos de competitividade e longevidade, zona de interesse do Relato Integrado (RI), um instrumento de comunicação da organização junto a seus stakeholders, que conecta informações financeiras (contabilidade) e "não financeiras", pelo uso de seis tipos capital que uma empresa gerencia e/ou impacta: financeiro, intelectual, de manufatura, de relacionamento, natural e humano. Diante desse contexto, o propósito deste artigo é avaliar como o capital humano está sendo evidenciado no Relato Integrado, por meio da frequência dos termos oriundos das referências de Demo et al. (2011) sobre gestão de pessoas e dos fundamentos do Relato Integrado. Para tanto, foram analisados os Relatos Integrados de onze empresas que fazem parte do programa piloto de RI no Brasil. A pesquisa é qualitativa e exploratória com análise de dados realizados por meio do software Atlas Ti 6.2. Os resultados indicam que oito das onze empresas analisadas contemplam políticas e práticas de Gestão de Pessoas (GP) nos seus relatórios, independentemente da denominação do relatório. Outra constatação é que, dos itens de GP abordados no referencial teórico, os dois com maior frequência nos relatos são treinamento e avaliação de desempenho, e os menos frequentes são recompensas e recrutamento \& seleção. Por fim, Governança e Ética não são os itens que mais se destacam como motivadores do Capital Humano.

Palavras-chave: Relato Integrado; Gestão de Pessoas; Capital Humano; Governança.

\section{Aspects of people management and human capital shown in integrated report}

\begin{abstract}
Assuming that human capital is crucial for the development of an organization, its disclosure is relevant to evaluate and understand the value creation in terms of competitiveness and longevity of this organization, area of interest of the Integrated Reporting (RI), an instrument of organizational communication joined to its stakeholders, which connects financial information (accounting) and "non-financial", the use of six capital types that an organization manages and / or impact: financial, intellectual, manufacturing, relationship, natural and human. In this context, the purpose of this article is to evaluate how human capital is being evidenced in the Integrated Report, by the frequency of terms coming of Demo et al references. (2011) on management of people and grounds of Integrated Reporting. To this end, the Integrated Reports were analyzed in eleven companies that are part of the RI pilot program in Brazil. The research is qualitative and exploratory with data analysis performed by the software Atlas Ti 6.2. The results indicate that eight of the eleven companies analyzed include policies and people management practices in their reports, regardless of the report name. Another finding is that the GP of items covered in the theoretical framework, the two most frequently in the reports are training and performance assessment; and the less frequent are rewards and recruitment \& selection. Finally, Governance and Ethics are not the items that stand out as motivators of human capital.
\end{abstract}

Keywords: Integrated Reporting; Management; Human Capital; Governance.

\section{Topic: Recursos Humanos}

Reviewed anonymously in the process of blind peer.

Claudemir Bertuolo Furnielis

Universidade Municipal de São Caetano do Sul, Brasil

http://lattes.cnpq.br/8846786059542387

cbertuolo@uol.com.br

Nadson Jaime Ferreira Alves

Centro Universitário do Estado do Pará, Brasil

http://lattes.cnpq.br/3690032231114353

nadson@ufpa.br

Edson Keyso de Miranda Kubo

Universidade Municipal de São Caetano do Sul, Brasil

http://lattes.cnpq.br/7102839820358192

edsonkubo@uscs.edu.br
Received: 09/10/2017

Approved: 09/12/2017

Eduardo de Camargo Oliva

Universidade Municipal de São Caetano do Sul, Brasil http://lattes.cnpq.br/9172181753057349

eduardo.oliva@uscs.edu.br
Referencing this:

FURNIELIS, C. B.; ALVES, N. J. F.; KUBO, E. K. M; OLIVA, E. C.. Aspectos da gestão de pessoas e do capital humano evidenciados no relato integrado. Revista Brasileira de Administração Científica, v.8, n.3, p.59-72, 2017. DOI: http://doi.org/10.6008/SPC2179$684 X .2017 .003 .0005$ 


\section{INTRODUÇÃO}

Segundo Calderón et al. (2012), o capital humano é o ativo responsável por grande parte do valor que o mercado atribui a uma organização pois ele é o elemento mais importante para o crescimento das firmas. Trata-se do conhecimento das pessoas, suas experiências e o 'know-how' adquiridos pela experiência e educação. E, para que a empresa possa desenvolver as capacidades para a obtenção de vantagem competitiva por meio do capital humano são necessárias práticas de gestão de pessoas, pois estas impulsionam o valor do capital humano (CHADWICK, 2017).

Em outra frente, por afetar o valor das organizações, o capital humano também desperta atenção dos stakeholders, agentes com interesses legítimos em relação ao cotidiano da empresa (sindicatos, entidades governamentais e não governamentais, concorrentes, investidores e a sociedade em geral). Assim, informações disponibilizadas aos stakeholders relacionadas ao capital humano servem tanto para uma análise das políticas de gestão, identificar o efeito na produtividade, competitividade e longevidade da firma.

No entanto, nem sempre o grau de importância das informações estão em sintonia com a disponibilidade das mesmas para os stakeholders, dentro do processo de boas práticas de governança corporativa que implica em contemplar quatros princípios basilares: transparência das informações, equidade no acesso, responsabilidade pelas divulgações e conformidade com normas e regulamentos que garantam a sustentabilidade da organização.

Nesse contexto, o Relato Integrado (RI) se apresenta como um processo que inova a comunicação empresarial ao integrar informações financeiras (contabilidade) com informações 'não financeiras' (governança, estratégia, sustentabilidade), para avaliar a criação de valor no decorrer do tempo, a partir da gestão dos seis capitais que a empresa gerencia ou impacta, em maior ou menor escala, para manter suas atividades: financeiro, intelectual, manufaturado, de relacionamento, natural e humano.

Diante da diversidade de informações em relação a esses capitais, é possível construir uma matriz de materialidade para identificar os temas mais relevantes para a diretoria da empresa e seus principais stakeholders. Portanto, o Relato Integrado potencializa a divulgação das práticas de Gestão do Capital Humano e dessa assertiva nasceu o problema de investigação deste estudo: o que tem sido comunicado sobre gestão de pessoas, a título de Capital Humano, no Relato Integrado?.

Apoiado na revisão bibliográfica, abordando os principais conceitos sobre Gestão de Pessoas, Governança Corporativa e Relato Integrado, esta pesquisa qualitativa, de caráter exploratório, com o uso do software Atlas Ti 6.2, analisou onze Relatos Integrados e identificou a frequência de políticas e práticas de Gestão de Pessoas comunicadas aos stakeholders, com base nas referências de Demo et al. (2011). 0 artigo contribui com a literatura à medida que demonstra que, embora seja considerado com fator fundamental, nem todas as firmas incluem políticas e práticas de GP em seus relatórios. 


\section{REVISÃO TEÓRICA}

\section{Gestão de Pessoas}

A firma, assim como tudo que a move, é essencialmente fruto da atividade humana, formada pela sua existência no espaço e no tempo. assim, para qualquer análise que se pretenda em relação às organizações, essas passam direta ou indiretamente pela compreensão da natureza e do ambiente em que o ser humano está envolvido (CALDERÓN et al., 2012). De acordo com Calderón et al. (2012), a teoria das relações humanas, inaugurada por Elton Mayo em meados do século 20, validou o conceito de 'homem social' no ambiente das empresas e esta perspectiva valida o conceito de capital humano como um articulador da consecução de objetivos econômicos e não econômicos da firma em seu ambiente de atuação.

Para Hitt et al. (2002), o capital humano geralmente é o reflexo da educação, experiência e habilidades identificadas em um indivíduo, conceitos que são corroborados por Calderón et al. (2012), ao afirmarem que o capital humano trata de capacidades produtivas que definem um indivíduo pela acumulação de conhecimentos, sendo um inventário intangível da pessoa que a domina, envolvendo a educação e a formação recebida, mas também a capacidade dessa pessoa em realizar atividades produtivas baseadas em competências adquiridas.

Hitt et al. (2002) diz que os investimentos em recursos intangíveis como o capital humano são apropriados e importantes, porque proporcionam aumentos significativos no valor da empresa a longo prazo. no entanto, para que as empresas possam alcançar o potencial pleno do capital humano, ele deve ser efetivamente gerenciado por meio de práticas de recursos humanos que melhorem as habilidades, a motivação e as oportunidades para o desenvolvimento dos funcionários (VOMBERG et al., 2015; GREER et al., 2017).

Para César et al. (2006) os funcionários são a mola propulsora para viabilizar os negócios de uma empresa e, como grupo, formam um capital gerador de valor e de alto significado competitivo com pouca possibilidade de imitação, por isso, o processo de gestão de pessoas (GP) assume grande importância no dia a dia das organizações, sendo uma das áreas mais significativas para a consecução das metas empresariais (AMORIN et al., 2012), embora apresente desafios e dilemas únicos para o gerenciamento em comparação a outros tipos de recursos (CHADWICK, 2017).

O processo de GP implica a atuação gerencial no sentido de conseguir que os funcionários atuem cooperativamente para atingir os objetivos da organização e os seus próprios, por meio de um conjunto de políticas e ações que garantam vantagem competitiva à firma (AZEVEDO et al., 2012). Trata-se de políticas que se concretizam à medida que os gestores departamentais a entendem como uma prática descentralizada, ou seja, não é função de um departamento em específico, mas um processo de administração que na sua particularidade setorial encontra-se alinhada ao negócio (BECKER et al., 2001). Assim, a GP deve permear toda a rotina de gerenciamento com o objetivo de conseguir melhores resultados (TACHIZAWA et al., 2001; BALCEIRO et al., 2003).

Para que as ações de GP sejam efetivas, os funcionários devem ser vistos como parceiros, participando das decisões, das ações empreendedoras e dos processos de inovação (RIBEIRO, 2006), até 
porque a empresa só pode alugar o capital humano e nunca comprá-lo por ser passível de transferência para uma outra firma concorrente (CHADWICK, 2017). Nesta perspectiva, deve-se ter o colaborador como sujeito participante das estratégias organizacionais e a GP como mobilizadora de recursos, assumindo a dianteira no processo de desenvolvimento de capacidades internas (DEMO et al., 2011; AMORIN et al., 2012).

De acordo com estudos de DEMO et al. (2011), para que a firma possa enfrentar a competitividade concorrencial são necessárias as seguintes políticas e práticas de GP para garantir a criação de capacidades organizacionais diferenciadas: Recrutamento e seleção: responsável pela identificação, atração e escolha dos indivíduos mais preparados para preencher os cargos da firma; Envolvimento: criação de vínculo afetivo com os funcionários, contribuindo em termos de reconhecimento, relacionamento, participação e comunicação; Treinamento, desenvolvimento e educação: ações para adquirir competências e estímulo a aprendizagem e produção de conhecimento;

Além dessas já citadas, têm-se: Condições de trabalho: promoção de boas condições de trabalho aos funcionários no que tange a benefícios, saúde, segurança e tecnologia; Avaliação de desempenho e competências dos funcionários: suporte para as promoções e planejamento de carreira e desenvolvimento; e Recompensas: ações que visam retribuir o desempenho e as competências dos colaboradores em termos de remuneração e incentivos.

Por certo, de acordo com o exposto, a prática de GP dá maior ganho de capacidade à empresa que a contempla em suas estratégias e, por conseguinte, obtém melhores resultados porque por meio das pessoas é que as soluções para a inovação, produtividade, melhoria nos processos de qualidade e atendimento a clientes e, ainda redução de custos se concretizam (FERREIRA et al., 2009). Se as práticas de Gestão de Pessoas podem reduzir custos e alavancar resultados, interessa aos stakeholders conhecer a contribuição dessa variável na criação de valor da empresa, interesse que vai ser favorecido com a Governança Corporativa.

\section{Governança Corporativa}

A vida das organizações é permeada por uma infinidade de eventos e obrigações junto à sociedade, como a prestação de contas de suas ações para com os grupos sociais que mantém interesses na condução dos negócios empresariais e reivindicam seu papel na cadeia de relacionamento (FOMBRUN et al., 2004), os stakeholders.

Rossetti et al. (2014) elencam quatro diferentes grupos de stakeholders: Shareholders - proprietários e investidores que demandam diferentes informações em função de especificidades quanto ao tipo de participação, ingerência na gestão, classe de ação etc.; Internos - direção executiva, conselho de administração, conselho fiscal, auditores independentes, auditores internos; Externos - credores, fornecedores, clientes, consumidores; e Entorno - comunidades locais, sociedade como um todo, governos e organizações não governamentais - ONGs.

Para atender a essas demandas, as empresas e seus gestores devem fazer uso de mecanismos que possam atender as expectativas desses grupos de forma a estabelecer relacionamentos capazes de gerar 
valor para eles (DOLPHIN, 2004). A Governança Corporativa - GC é uma das estratégias utilizadas pelas firmas de capital aberto com o objetivo de ter melhores resultados para suas ações por meio de informações transparentes prestadas pelos administradores a seus acionistas (BIRK, 2012). De acordo com o IBCG (2011),

Governança Corporativa é o sistema pelo qual as organizações são dirigidas, monitoradas e incentivadas, envolvendo os relacionamentos entre proprietários, Conselho de Administração, Diretoria e órgãos de controle. As boas práticas de Governança Corporativa convertem princípios em recomendações objetivas, alinhando interesses com a finalidade de preservar e otimizar o valor da organização, facilitando seu acesso a recursos e contribuindo para sua longevidade.

Para a Comissão de Valores Mobiliários - CVM, as práticas de GC garantem uma harmonia entre os interesses dos públicos envolvidos com a empresa, facilitando o acesso aos dados e contribuindo para que os investidores possam avaliar os riscos ao se decidirem ou não pela compra de ações de uma firma (CVM, 2002). O investidor necessita de informações para comparar as diversas opções de investimentos, e quanto mais evidentes forem as informações, melhor para a decisão (NARDI et al., 2008).

O IBCG (2009) apresenta os quatro princípios básicos da Governança Corporativa responsáveis por alinhar interesses, preservar e otimizar o valor da organização: a transparência que visa disponibilizar informações de interesse para as partes e não somente as exigidas pela legislação, algo além do desempenho econômico-financeiro, inclusive os intangíveis que norteiam a ação gerencial e conduzem a criação de valor; a equidade que visa garantir tratamento igualitário para acesso às informações por todos os públicos interessados nos negócios da organização (stakeholders).

Em continuação, a prestação de contas que remete à responsabilidade dos agentes de governança em prestar contas de sua atuação, assumindo integralmente as consequências de seus atos e omissões; a responsabilidade corporativa que atribui aos agentes de governança o zelo pela sustentabilidade das organizações, visando a longevidade desta, incorporando considerações de ordem econômica, social e ambiental (triple botton line) na definição dos negócios e operações.

Nesse contexto, surgiu o Relato Integrado, um processo de comunicação empresarial inspirado na necessidade de conectar o Relatório de Governança Corporativa que ganhou relevância em função da Lei Sarbanes Oxley, após os escândalos financeiros que abalaram os EUA; o Relatório de Sustentabilidade inspirado nas orientações da Global Reporting Initiative (GRI); o Relatório de Administração que evidencia o modelo de negócio e as estratégias da empresa; bem como o Relatório Financeiro que vem sendo aprimorado no processo de Convergência às Normas Internacionais de Contabilidade, capitaneados pelo International Accounting Standards Board (IASB).

\section{Relato Integrado}

O IIRC (2013) define o Relato Integrado como um processo que resulta na comunicação contínua, por uma organização, evidenciando a forma como a administração desenvolve as atividades empresariais e seus efeitos na geração de valor ao longo do tempo. Atualmente, 146 empresas no mundo, sendo 12 do Brasil, participam do programa piloto de experimentação do Relato Integrado. 
Trata-se de uma comunicação clara e concisa que deve destacar a visão da organização quanto ao ambiente externo, a governança, as oportunidades e riscos, a estratégia e alocação de recursos, o modelo de negócios, o desempenho, o panorama futuro e as bases utilizadas para preparação e apresentação de informações (IIRC, 2013).

O RI tem como princípios: o foco na estratégia para orientação futura do negócio, na conectividade das informações, no relacionamento com as partes interessadas, na materialidade e concisão das informações, na confiabilidade e completude do que é divulgado e na consistência de procedimentos que permitam a comparabilidade (IIRC, 2013).

O objetivo é catalisar uma abordagem mais coesa e eficiente para relatórios corporativos, ao comunicar a gama de fatores que afetam materialmente a capacidade de uma organização gerar valor, com destaque aos diversos tipos de capital. Assim, a principal característica do RI é sua abrangência em relação a áreas e fatores da empresa, para atender uma demanda, cada vez maior, de investidores e credores, que buscam transparência nas informações sobre os recursos aplicados pela entidade (PEREZ JÚNIOR et al., 2014).

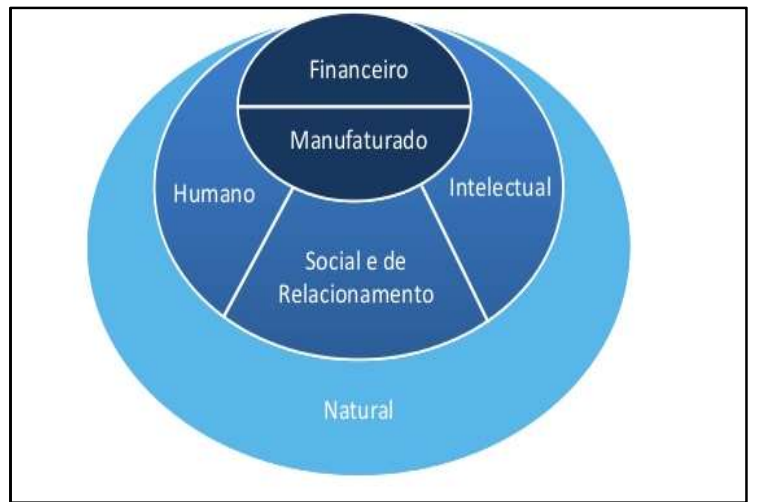

Figura 1: Tipos de Capital evidenciados no Relato Integrado.

Destrinchando de forma explicativa a figura 1, temos que: Financeiro: refere-se a investimentos, dívidas e capital que permitem a organização produzir de bens e prestar serviços; Intelectual: conhecimento em posse da empresa e a capacidade em saber mantê-lo e expandi-lo; Manufatura: infraestrutura física fabricada que a empresa utiliza como máquinas, edificações etc.; Humano: competências, capacidades, experiências e motivações dos colaboradores para buscar melhorias contínuas; Natural: todos os recursos naturais utilizáveis pela organização, renováveis e não renováveis; e Social e de Relacionamento: Relação entre a organização e a comunidades e outras partes interessadas. A questão é entender as interações entre os diferentes capitais e setores da companhia, pois segundo o IIRC (2013), há um fluxo constante entre e dentro dos capitais à medida que eles aumentam, diminuem ou se transformam.

Quando uma organização investe em capacitação de empregados, os custos incorridos reduzem seu capital financeiro e potencializam o capital humano. Isso reflete interações e transformações contínuas entre capitais, embora com diferentes taxas e impactos entre estes e outros capitais: potencial aumento da autoestima (capital humano), tendência à melhoria no desempenho (capital financeiro), incremento na gestão de conhecimentos (capital intelectual), por exemplo. E o efeito líquido dessa variação também 
depende da perspectiva escolhida, empregados e empregadores podem valorizar a capacitação de maneiras diferentes, daí a importância da matriz de materialidade no sentido de ponderar diferentes perspectivas.

Segundo Eccles et al. (2011), essa lógica também funciona no sentido identificar lacunas e medidas corretivas, que somente a evidenciação do capital financeiro não conseguiria abarcar, pois ao orquestrar informações dos seis capitais, vão vir à tona questões que a estratégia da empresa e seu desdobramento em operações serão encorajadas a corrigir. Por exemplo, quais as medidas da organização diante da necessidade de oferecer empregos economicamente viáveis e significativos para bilhões de pessoas excluídas do consumo básico? Quais as ações efetivas desta organização quanto a importância de fazer o melhor uso possível do capital humanos em uma economia de conhecimento? É a substituição do foco preso ao desempenho financeiro de curto prazo, por uma visão de mais longo prazo, que reconheça "uma empresa sustentável depende de sua contribuição para uma sociedade sustentável" (ECCLES; et al., 2011).

Dessa forma fica mais evidentes a identificação de pontos fortes e pontos fracos no contexto do que vem a ser oportunidades e ameaças para a organização. No caso específico do Capital humano, o IIRC (2013) prevê a divulgação das seguintes competências, habilidades e experiências das pessoas e suas motivações para inovar, incluindo: Alinhamento e apoio à estrutura de governança, ao gerenciamento de riscos e aos valores éticos; Capacidade de entender, desenvolver e implementar a estratégia de uma organização; e Lealdade e motivação para melhorar processos, bens e serviços, incluindo a capacidade de liderar, gerenciar e colaborar.

Ao integrar dados financeiros com 'não financeiros' conexos ao capital humano, a tendência é ter informações mais consistentes para analisar os custos operacionais de uma decisão considerando os impactos sociais, ambientais e econômicos. Isso fortalece a Gestão TBL (Triple Botton Line), pois potencializa a eficiência no uso dos recursos, ajuda a fundamentar as decisões estratégicas e operacionais e evita a divergência de informações entre os relatórios empresariais, pois a sinergia entre os capitais requer o entendimento da relação de causa e efeito entre eles. É a construção do pensamento integrado. Portanto, o Relato Integrado é uma prática em construção que requer estudos que detalhem as diversas variáveis que estão em jogo na construção do valor da empresa, como é o caso do Capital Humano e seus desdobramentos nas práticas de Gestão de Pessoas.

\section{METODOLOGIA}

Trata-se de uma pesquisa exploratória sobre a evidenciação do capital humano no Relato Integrado, por meio da frequência dos termos oriundos das referências de Demo et al. (2011) sobre gestão de pessoas e dos fundamentos do Relato Integrado. O propósito é fornecer uma visão geral sobre o fato pesquisado, principalmente quando há poucos dados à disposição do pesquisador em relação ao tema e/ou não está definidamente sistematizado (VERGARA, 2004; ALYRIO, 2008).

Este tipo de pesquisa permite conseguir melhor compreensão e intimidade com o fenômeno, ampliando a experiência do pesquisados em relação ao problema (TRIVIÑOS, 2008). Por essa razão, a pesquisa exploratória caracteriza-se como qualitativa, por permitir ao pesquisador partir de proposições mais 
amplas e que vão se delineando à medida em que o trabalho vai se desenvolvendo (GODOY, 2007). Conforme Creswel (2010), a pesquisa qualitativa acontece no ambiente natural do objeto de estudo, admite o envolvimento do pesquisador na coleta dos dados e é fundamentalmente interpretativa.

Também se caracteriza como pesquisa documental (Relato Integrado/2014), ao considerar o aspecto temporal e a influência do contexto na análise, para observar mudanças nos indivíduos, grupos, conceitos, conhecimentos, comportamentos, práticas e mentalidades (CELLARD, 2008). O universo de pesquisa é composto pelas empresas que participam do programa piloto do Relato Integrado, no Brasil: AES Brasil (Energia); BNDES (Bancos); BR Foods (Alimentos); CCR S.A. (Transportes); CPFL Energia; Fibria (Celulose); Itaú (Bancos); Mapfre/Banco do Brasil (Seguros); Natura (Varejo); Petrobras (Óleo e Gás); Via Gutenberg (Entretenimento e cultura) e Votorantin Industrial (Serviços Financeiros).

A coleta de dados foi via fontes secundárias, com auxílio do software Atlas Ti 6.2 for Windows, que suporta métodos de pesquisa qualitativos e mistos e permite reunir, organizar e analisar conteúdos documentais. Esse software permite analisar dados em detalhes utilizando ferramentas de busca, consulta e visualização, possibilitando ao pesquisador estabelecer conexões, acrescentar suas percepções e ideias enquanto trabalha e justifica descobertas com rigor.

\section{RESULTADOS E DISCUSSÃO}

Para localizar os Relatos Integrados das empresas do programa piloto referente ao exercício de 2014, verificou-se a disponibilidade dos documentos nos respectivos sítios eletrônicos durante o período da coleta de dados: novembro/2016. Neste período, os relatórios da Via Gutenberg não foram localizados; por esta razão, esta empresa foi excluída da análise.

Em razão dos requisitos estabelecidos, onze empresas encontravam-se aptas para serem estudadas: AES Brasil (AES); BRF S.A. (BRF); CCR S.A. (CCR); CPFL Energia (CPFL); Fibria Celulose S.A. (FIBRIA); Itaú Unibanco (ITAU); Grupo Segurador Banco do Brasil/Mapfre (MAPFRE); Natura (NAT); Petrobrás (PETRO) S.A.; Banco Nacional de Desenvolvimento Econômico e Social (BNDES) e Votorantim (VOT). Alguns relatórios não se intitulam Relato Integrado, mas Relatório de Sustentabilidade ou Relatório Anual, ainda assim anunciam que seguem os preceitos do Relato Integrado, por isso foram considerados, conforme demonstra quadro 1.

Quadro 1: Produção do Relato Integrado.

\begin{tabular}{|c|c|c|c|c|c|c|}
\hline \multirow[t]{2}{*}{ Empresa } & \multirow[t]{2}{*}{ Segmento } & \multirow{2}{*}{$\begin{array}{c}\text { Tipo * } \\
\text { RI, RS, RA }\end{array}$} & \multicolumn{2}{|c|}{ Disponível } & \multirow[t]{2}{*}{ Exercício 2014} & \multirow[t]{2}{*}{ Número de páginas } \\
\hline & & & PDF & Site & & \\
\hline AES Brasil & Energia & RS & $\mathrm{x}$ & $\mathrm{X}$ & $\mathrm{X}$ & 40 \\
\hline BNDES & Bancos & RA & $x$ & $x$ & $x$ & 29 \\
\hline BR Foods & Alimentos & RS & $\mathrm{X}$ & $\mathrm{X}$ & $\mathrm{x}$ & 117 \\
\hline CCR S.A. & Transportes & RS & $\mathrm{X}$ & $\mathrm{X}$ & $\mathrm{X}$ & 24 \\
\hline CPFL Energia & Energia & RS & $\mathrm{x}$ & $x$ & $x$ & 71 \\
\hline Fibria & Celulose & $\mathrm{RI}$ & $x$ & $x$ & $x$ & 152 \\
\hline Itaú & Bancos & $\mathrm{RI}$ & $x$ & $x$ & $x$ & 37 \\
\hline Mapfre/Banco do Brasil & Seguros & RS & $\mathrm{x}$ & $x$ & $\mathrm{X}$ & 56 \\
\hline Natura & Varejo & $\mathrm{RI}$ & $\mathrm{x}$ & $x$ & $x$ & 21 \\
\hline Petrobras & Óleo e Gás & RS & $x$ & $x$ & $\mathrm{x}$ & 81 \\
\hline Via Gutenberg & Consultoria & - & - & - & - & - \\
\hline Votorantin Industrial & Serviços Financeiros & $\mathrm{RI}$ & $\mathrm{X}$ & $X$ & $X$ & 168 \\
\hline
\end{tabular}

Legenda: RI - Relato Integrado; RS - Relatório de Sustentabilidade; RA - Relatório Anual. 
Através do software Atlas Ti 6.2 foi possível verificar a frequência dos códigos e a predominância das ideias no RI com base nas políticas e práticas de GP de Demo et al. (2011), conforme apresentado no Quadro 1. Os códigos 'recrutamento' e 'seleção' são os que menos aparecem considerando todas as políticas e práticas de GP, com 67 frequências no total. Destaque ao termo 'seleção' que recebe 14 e 10 citações nos relatos das empresas Petrobrás e Mapfre, respectivamente. Ainda, referente a este ponto, ressalta-se que as palavras não aparecem nenhuma vez no relatório da firma AES.

O maior número de citações se encontram nas ações de estímulo à aprendizagem e produção de conhecimento, com 910 códigos para 'treinamento, desenvolvimento e educação', evidenciando 598 manifestações para "desenvolvimento" e 211 para 'treinamento'. O RI do BNDES apresenta a maior frequência destas palavras, totalizando 156 presenças e a menor se encontra no relatório da empresa de energia AES Brasil, 25.

As políticas e práticas de GP relacionadas à "avaliação de desempenho e competências", considerando a frequência das palavras 'autoavaliação', 'avaliação', 'desempenho' e 'carreira' totalizam 824 frequências. Neste quesito, os códigos linguísticos aparecem em maior número na empresa Votorantim, 123, e em menor número na empresa AES, 9. As 'condições de trabalho em termos de benefícios, saúde e segurança' totalizam 713 aparecimentos nos RI, com destaque para a empresa BRF, com 129 repetições e 12 para AES. A palavra 'tecnologia' associada, por Demo et al. (2011), às condições de trabalho, não aparece nos relatos.

A política e prática de 'bem-estar' que contempla 'reconhecimento, relacionamento, participação e comunicação'; tem menção apenas das palavras 'comunicação' e suas conjugações verbais e 'reconhecimento', em um total de 259 repetições. No entanto, destaca-se que 'comunicação' aparece em diversas dimensões dos relatórios e não somente dentro de 'Capital Humano', o que inviabiliza qualquer leitura mais profunda. O termo 'Relacionamento e participação' não aparecem nos RI. Dentro de 'recompensas' encontra-se apenas 143 frequências para 'remuneração' e 1 para 'recompensa'. A empresa que mais trata de remuneração em seu RI é o Banco Itaú e a que menos cita é a Natura, apenas uma.

Foi constado que o termo 'capital humano' aparece 35 vezes nos relatos, estando grafada em 12 momentos no RI da CPFL; 9 da CCR; 5 na BRF; 4 no Banco Itaú; 3 na empresa Votorantim e 2 na Fíbria; nas demais empresas o termo não aparece. Apesar de que, no Framework do Relato Integrado, as empresas não são obrigadas a estruturar um tópico para cada capital, podendo retratar os conteúdos dos capitais na forma que achar mais adequada. No entanto, é possível encontrar as palavras 'humano' e 'gente' em um total de 208 frequências, sendo que 40 delas estão no relatório da empresa Votorantim e 30 na Petrobrás. No relatório da empresa AES não aparecem 'capital humano', nem 'humano' e nem 'gente'.

Destaca-se que, do total de 2.917 frequências dos termos relacionados a Capital Humano e Gestão de Pessoas presentes nos relatos das 11 empresas analisadas, os códigos linguísticos que mais aparecem estão nos RI da Mapfre, CPFL e Votorantim, com 394, 391 e 387 representações, respectivamente. As últimas, com 58 e 88 constâncias, estão os Relatos das empresas AES e Natura. 
De todo o exposto e ponderando as frequências disponibilizadas pelo software Atlas Ti 6.2 é possível interpretar que os relatórios das empresas AES e Natura são os mais "fora da curva" e, destas duas, o da empresa Natura lidera porque mesmo se intitulando RI, conforme consta no quadro 1, é o penúltimo na presença de políticas e práticas de GP e, ainda, não é possível encontrar nenhuma manifestação sobre 'capital humano' e este é um dos pontos fundamentais do RI, conforme descrito na literatura.

Também, que não há relação entre a categoria em que o relatório se insere - Relato Integrado, Relatório de Sustentabilidade, Relatório Anual - e as práticas de Gestão de Pessoas, de acordo com a frequência de códigos e discussões de Demo et al. (2011). Ainda, dos 4 relatos que se apresentam como RI, apenas o da empresa Votorantim está entre os três com maior predominância da ideia de GP e liderando a menção a "humano" e "gente" podendo ser eleito como o mais próximo entre a literatura e a prática, enquanto o da Natura como o mais distante, considerando os termos estratificados pelo Software Atlas TI, conforme demonstra tabela 1.

Tabela 1: Frequência de códigos dos itens de Gestão de Pessoas.

\begin{tabular}{|c|c|c|c|c|c|c|c|c|c|c|c|c|}
\hline & CPFL & BNDES & FIBRIA & ITAÚ & Votorantim & Natura & CCR & AES & BRF & Mapfre & Petrobrás & Total \\
\hline \multicolumn{13}{|l|}{ Capital Humano } \\
\hline Humano (s) & 22 & 3 & 15 & 9 & 24 & 6 & 27 & 0 & 25 & 24 & 30 & 185 \\
\hline \multirow[t]{2}{*}{ Gente } & 0 & 0 & 2 & 0 & 16 & 0 & 0 & 0 & 4 & 1 & 0 & 23 \\
\hline & 22 & 3 & 17 & 9 & 40 & 6 & 27 & 0 & 29 & 25 & 30 & 208 \\
\hline \multicolumn{13}{|l|}{ Recrutamento e Seleção } \\
\hline Recrutamento & 1 & 0 & 0 & 2 & 3 & 0 & 1 & 0 & 1 & 1 & 0 & 9 \\
\hline Seleção & 5 & 4 & 5 & 2 & 7 & 2 & 0 & 0 & 6 & 10 & 14 & 55 \\
\hline \multirow[t]{2}{*}{ Currículo ou Curriculum } & 2 & 0 & 0 & 0 & 0 & 0 & 1 & 0 & 0 & 0 & 0 & 3 \\
\hline & 8 & 4 & 5 & 4 & 10 & 2 & 2 & 0 & 7 & 11 & 14 & 67 \\
\hline \multicolumn{13}{|l|}{ Bem-estar } \\
\hline $\begin{array}{l}\text { Comunicação e suas } \\
\text { conjugações verbais }\end{array}$ & 39 & 8 & 15 & 14 & 27 & 10 & 11 & 6 & 18 & 41 & 25 & 214 \\
\hline \multirow[t]{2}{*}{ Reconhecimento (s) } & 6 & 2 & 5 & 4 & 6 & 2 & 2 & 3 & 8 & 6 & 1 & 45 \\
\hline & 45 & 10 & 20 & 18 & 33 & 12 & 13 & 9 & 26 & 47 & 26 & 259 \\
\hline \multicolumn{13}{|l|}{ Treinamento } \\
\hline Desenvolvimento & 52 & 140 & 63 & 43 & 52 & 32 & 29 & 12 & 55 & 57 & 63 & 598 \\
\hline Treinamento (s) & 20 & 11 & 18 & 28 & 39 & 2 & 1 & 10 & 27 & 39 & 16 & 211 \\
\hline \multirow[t]{2}{*}{$\begin{array}{l}\text { Capacitação e suas } \\
\text { conjugações verbais }\end{array}$} & 19 & 5 & 7 & 1 & 11 & 6 & 6 & 3 & 14 & 10 & 16 & 101 \\
\hline & 91 & 156 & 88 & 72 & 102 & 40 & 36 & 25 & 96 & 106 & 95 & 910 \\
\hline \multicolumn{13}{|l|}{ Condições de Trabalho } \\
\hline Benefício (s) & 15 & 15 & 11 & 12 & 10 & 7 & 6 & 0 & 13 & 22 & 12 & 123 \\
\hline Saúde & 40 & 18 & 21 & 14 & 31 & 0 & 5 & 2 & 55 & 43 & 44 & 273 \\
\hline \multirow[t]{2}{*}{ Segurança } & 56 & 8 & 19 & 24 & 50 & 5 & 8 & 10 & 61 & 29 & 47 & 317 \\
\hline & 111 & 41 & 51 & 50 & 91 & 12 & 19 & 12 & 129 & 94 & 103 & 713 \\
\hline \multicolumn{13}{|l|}{ Avaliação de Desempenho } \\
\hline Auto avaliação & 0 & 0 & 0 & 0 & 2 & 1 & 0 & 0 & 2 & 0 & 0 & 5 \\
\hline $\begin{array}{l}\text { Avaliação e suas conjugações } \\
\text { verbais }\end{array}$ & 48 & 26 & 57 & 44 & 62 & 5 & 16 & 7 & 51 & 51 & 43 & 410 \\
\hline Desempenho (s) & 56 & 13 & 42 & 19 & 51 & 14 & 65 & 1 & 26 & 62 & 20 & 369 \\
\hline \multirow[t]{2}{*}{ Carreira (s) } & 13 & 4 & 3 & 4 & 8 & 1 & 0 & 1 & 1 & 2 & 3 & 40 \\
\hline & 117 & 43 & 102 & 67 & 123 & 21 & 81 & 9 & 80 & 115 & 66 & 824 \\
\hline \multicolumn{13}{|l|}{ Recompensas } \\
\hline Remuneração (ações) & 19 & 9 & 5 & 22 & 27 & 1 & 4 & 3 & 16 & 21 & 16 & 143 \\
\hline \multirow[t]{2}{*}{ Recompensas } & 0 & 0 & 0 & 0 & 1 & 0 & 0 & 0 & 0 & 0 & 0 & 1 \\
\hline & 19 & 9 & 5 & 22 & 28 & 1 & 4 & 3 & 16 & 21 & 16 & 144 \\
\hline Total de frequências & 391 & 263 & 271 & 233 & 387 & 88 & 155 & 58 & 354 & 394 & 320 & 2917 \\
\hline
\end{tabular}

Como complemento à análise, tem-se na tabela 2 um conjunto de palavras que, podem evidenciar questões do "capital humano" embora aqui esteja destacado separadamente por não serem contemplados 
diretamente na literatura de Demo et al. (2011). As maiores frequências aparecem nas empresas CPFL, BRF e Petrobrás, com 77, 64 e 61 presenças, respectivamente. E, nas últimas colocações, CCR com 12, AES com 10 e Natura com 8.

Tabela 2: Frequência de códigos dos complementares à Gestão de Pessoas.

\begin{tabular}{|l|r|r|r|r|r|r|r|r|r|r|r|r|}
\hline & CPFL & BNDES & FIBRIA & ITAÚ & Votorantim & Natura & CCR & AES & BRF & Mapfre & Petrobrás & Total \\
\hline Absenteísmo & 2 & 3 & 0 & 1 & 1 & 0 & 0 & 0 & 1 & 2 & 1 & 11 \\
\hline Acidente(s) & 32 & 4 & 6 & 3 & 13 & 0 & 3 & 6 & 20 & 13 & 20 & 120 \\
\hline Aposentadoria & 4 & 0 & 2 & 0 & 1 & 0 & 0 & 0 & 1 & 2 & 5 & 15 \\
\hline $\begin{array}{l}\text { Aprendizado e suas } \\
\text { conjugações verbais }\end{array}$ & 2 & 4 & 2 & 3 & 5 & 4 & 0 & 0 & 3 & 2 & 2 & 27 \\
\hline Aprendiz(es) & 1 & 0 & 1 & 5 & 4 & 0 & 1 & 0 & 4 & 6 & 2 & 24 \\
\hline Beneficiário(s) & 2 & 7 & 1 & 0 & 3 & 0 & 0 & 2 & 0 & 2 & 1 & 18 \\
\hline Competência(s) & 18 & 12 & 2 & 3 & 2 & 3 & 4 & 1 & 8 & 4 & 5 & 62 \\
\hline Demissão(ões) & 1 & 0 & 0 & 1 & 0 & 0 & 0 & 0 & 0 & 0 & 0 & 2 \\
\hline Gênero(s) & 6 & 7 & 0 & 1 & 9 & 0 & 0 & 0 & 9 & 2 & 16 & 50 \\
\hline Incentivo(s) & 5 & 2 & 1 & 7 & 11 & 1 & 3 & 1 & 6 & 8 & 4 & 49 \\
\hline Saudável(eis) & 1 & 1 & 1 & 3 & 4 & 0 & 1 & 0 & 11 & 2 & 5 & 29 \\
\hline Turnorver & 3 & 0 & 0 & 1 & 1 & 0 & 0 & 0 & 1 & 0 & 0 & 6 \\
\hline Total de frequências & $\mathbf{7 7}$ & $\mathbf{4 0}$ & $\mathbf{1 6}$ & $\mathbf{2 8}$ & $\mathbf{5 4}$ & $\mathbf{8}$ & $\mathbf{1 2}$ & $\mathbf{1 0}$ & $\mathbf{6 4}$ & $\mathbf{4 3}$ & $\mathbf{6 1}$ & $\mathbf{4 1 3}$ \\
\hline
\end{tabular}

A tabela 3, também com base em análise das frequências dos códigos capturados pelo software Atlas TI 6.2, apresenta informações sobre Capital Humano que, de acordo com IIRC (2013) diz respeito às motivações que a empresa tem para a inovação, incluindo: capacidade estratégica; governança e ética; motivação e liderança.

Nos relatórios disponíveis o código 'inovação' e suas conjugações verbais aparecem 326 vezes, tendo a maior frequência no RI do BNDES, 82 e a menor na CCR e AES. Quando as palavras, 'capacidade' e 'estratégia', 'governança' e 'ética', 'motivação' e 'liderança' são agrupadas tomando-as como predominantes de uma ideia, tem-se os códigos Capacidade mais Estratégia aparecendo 788 vezes nos relatórios, sendo a empresa Votorantim a que mais as emprega, 121; e a Natura a que menos registra os termos com 45 citações. Enquanto os termos Governança e Ética, juntos totalizam 561 presenças nos RI, aparecendo 92 vezes no RI da CPFL e 11 no da Natura, o menor número. As palavras Motivação e Liderança totalizam 192 grafias, sendo mais mencionados pela empresa BRF; e a CCR a que traz menos registros.

Em uma análise geral, as três construções consideradas como motivadoras para a inovação, aparecem 1.541 vezes nos registros do software Atlas Ti 6.2. As empresas que mais as empregam são Votorantim, CPFL e BRF com 229, 201 e 172 registros, respectivamente; e as firmas que menos citam os termos em seus relatos são a Natura, com 71 apontamentos e a AES com 82 .

Tabela 3: Frequência de códigos de motivação para inovação.

\begin{tabular}{|c|c|c|c|c|c|c|c|c|c|c|c|c|}
\hline & $\begin{array}{c}\mathrm{CPF} \\
\mathrm{L}\end{array}$ & $\begin{array}{l}\text { BNDE } \\
\text { S }\end{array}$ & $\begin{array}{c}\text { FIBRI } \\
\text { A }\end{array}$ & $\begin{array}{l}\text { ITA } \\
\text { Ú }\end{array}$ & $\begin{array}{l}\text { Votoranti } \\
\mathrm{m}\end{array}$ & $\begin{array}{c}\text { Natur } \\
\text { a }\end{array}$ & $\begin{array}{l}\mathrm{CC} \\
\mathrm{R}\end{array}$ & $\begin{array}{l}\mathrm{AE} \\
\mathrm{S}\end{array}$ & $\begin{array}{c}\text { BR } \\
F\end{array}$ & $\begin{array}{l}\text { Mapfr } \\
\text { e }\end{array}$ & $\begin{array}{c}\text { Petrobrá } \\
\text { s }\end{array}$ & $\begin{array}{c}\text { Tota } \\
\text { I }\end{array}$ \\
\hline $\begin{array}{l}\text { Inovação e suas conjugações } \\
\text { verbais }\end{array}$ & 12 & 82 & 79 & 13 & 26 & 36 & 5 & 5 & 42 & 19 & 7 & 326 \\
\hline Governança & 53 & 19 & 22 & 26 & 48 & 4 & 62 & 8 & 34 & 50 & 27 & 353 \\
\hline \multirow[t]{2}{*}{ Ética } & 39 & 3 & 10 & 27 & 28 & 7 & 6 & 21 & 20 & 23 & 24 & 208 \\
\hline & 92 & 22 & 32 & 53 & 76 & 11 & 68 & 29 & 54 & 73 & 51 & 561 \\
\hline $\begin{array}{l}\text { Motivação e suas conjugações } \\
\text { verbais }\end{array}$ & 0 & 0 & 0 & 2 & 2 & 0 & 0 & 0 & 3 & 0 & 0 & 7 \\
\hline $\begin{array}{l}\text { Liderança e suas conjugações } \\
\text { verbais }\end{array}$ & 31 & 2 & 19 & 22 & 30 & 15 & 6 & 7 & 30 & 13 & 10 & 185 \\
\hline
\end{tabular}




\begin{tabular}{|l|r|r|r|r|r|r|r|r|r|r|r|r|}
\hline & $\mathbf{3 1}$ & $\mathbf{2}$ & $\mathbf{1 9}$ & $\mathbf{2 4}$ & $\mathbf{3 2}$ & $\mathbf{1 5}$ & $\mathbf{6}$ & $\mathbf{7}$ & $\mathbf{3 3}$ & $\mathbf{1 3}$ & $\mathbf{1 0}$ & $\mathbf{1 9 2}$ \\
\hline Capacidade & 21 & 16 & 16 & 15 & 35 & 8 & 14 & 18 & 8 & 8 & 3 & 162 \\
\hline $\begin{array}{l}\text { Estratégia e suas conjugações } \\
\text { verbais }\end{array}$ & 57 & 49 & 66 & 59 & 86 & 37 & 63 & 28 & 77 & 74 & 30 & 626 \\
\hline & $\mathbf{7 8}$ & $\mathbf{6 5}$ & $\mathbf{8 2}$ & $\mathbf{7 4}$ & $\mathbf{1 2 1}$ & $\mathbf{4 5}$ & $\mathbf{7 7}$ & $\mathbf{4 6}$ & $\mathbf{8 5}$ & $\mathbf{8 2}$ & $\mathbf{3 3}$ & $\mathbf{7 8 8}$ \\
\hline & $\mathbf{2 0 1}$ & $\mathbf{8 9}$ & $\mathbf{1 3 3}$ & $\mathbf{1 5 1}$ & $\mathbf{2 2 9}$ & $\mathbf{7 1}$ & $\mathbf{1 5 1}$ & $\mathbf{8 2}$ & $\mathbf{2}$ & $\mathbf{1 6 8}$ & $\mathbf{9 4}$ & $\mathbf{1}$ \\
\hline
\end{tabular}

Analisando os dados em conjunto, pelas frequências dos códigos e predominância de ideias presentes nos relatos, é possível destacar quatro constatações: As empresas CPFL (Energia), BNDES (Bancos), Fíbria (Celulose), Itaú (Bancos), Votorantim Industrial (Serviços Financeiros), BRF (Alimentos), Banco do Brasil/Mapfre (Seguros) e Petrobras (Óleo e Gás) atendem aos quesitos de GP e também à motivação do Capital Humano para a inovação. Em outra frente, o mesmo não se pode afirmar quanto ao que se observa nos relatos de 2014 das firmas CCR S.A. (Transportes); Natura (Varejo); AES Brasil (Energia).

Posteriormente, o tipo de relatório apresentado; se Relato Integrado, Relatório de Sustentabilidade ou Relatório Anual, não tem influência para os resultados anteriores uma vez que a empresa Natura considera o seu relatório como sendo integrado, assim como Fíbria, Itaú e Votorantim. No entanto, a empresa, está entre as três últimas colocadas, com base na análise de frequência; Dos quesitos de GP tomados de Demo et al. (2011), os dois com maior frequência nos relatórios são treinamento e avaliação de desempenho e os menos frequentes são recompensas e recrutamento e seleção; e Apesar dos percalços éticos que assolam o país, pelo menos nos relatórios de 2014, Governança e Ética não foram os itens com maior frequência na análise dos aspectos motivacionais do Capital humano para a inovação.

\section{CONSIDERAÇÕES FINAIS}

O propósito deste artigo foi avaliar como o Capital Humano está sendo comunicado no Relato Integrado, com base na literatura de Demo et al. (2011), que trata da Gestão de Pessoas, por meio da frequência dos termos. Logo, não estava em julgamento as ações efetivas das empresas citadas, mas as evidências de tais ações nos respectivos relatos integrados.

As análises foram baseadas na frequência de termos do referencial teórico no Relato Integrado, por meio do Software Atlas Ti 6.2, e dentre os princípios norteadores do Relato Integrado, dois merecem destaque o da materialidade \& concisão e o da confiabilidade \& completude, ou seja, para garantir a atratividade do relato perante seus usuários, a divulgação precisa ser mais concisa, por isso deve ser divulgado o que é material, sem comprometer a completude, caso contrário perde-se em confiabilidade. Dentre os relatos analisados, há variação no número de páginas, conforme demonstrou o quadro 1.

Também não entrou em julgamento o nível de conectividade das informações sobre capital humano em relação aos demais capitais, pois isso foge ao escopo deste estudo. Mas que pode ser aprofundado em futuras pesquisas. Mas o fato do capital humano ser crucial para criação de valor de uma empresa, seus aspectos precisam ser evidenciados tanto quanto os demais capitais, entretanto, a pesquisa identificou aspectos que não receberam nenhuma referência, o que já comprometeria a possibilidade de integração com as demais informações relevantes. 
O uso do Software Atlas Ti 6.2, contribuiu para sistematizar e dar visibilidades aos tópicos do referencial teórico tratados no RI. Assim foi possível identificar treinamento e avaliação como os tópicos mais frequentes, em detrimento de recompensas, recrutamento e seleção, ou mesmo que Governança e Ética não foram temáticas tão abordadas dentre os aspectos motivacionais, como sugere o Framework do Relato Integrado.

Portanto, o tratamento dos dados com base no referido software facilitou o processo de comparação dos Relatos das diversas empresas, gerando frequências nem sempre perceptíveis sem o auxílio dessa ferramenta. E o resultado alcançado, possibilita que cada organização equalize tais informações numa próxima edição do Relato Integrado, principalmente no caso em que existiram ações concretas, mas que não foram evidenciadas adequadamente no RI. Como limitador do estudo está o fato de que "quantidade não é sinônimo de qualidade", portanto, a presença dos termos em si, dentro do que diz Demo et al. (2011), não evidenciam necessariamente a profundidade e/ou dedicação dos gestores das firmas para com os temas. Ainda, que o fato de não aparecerem no RI, implica a não atenção por parte da empresa nos seus processos de Gestão de Pessoas.

O resultado atual também sinaliza para pesquisas futuras que permitam estudos mais profundos, como o mapeamento gráfico das principais categorias exploradas pelas respectivas empresas, e suas interrelações bem como a análise comparativa entre o que está no RI e a prática efetiva por meio de estudos de casos.

\section{REFERÊNCIAS}

ALYRIO, R. D.. Metodologia científica. Rio de Janeiro: UFRJ, 2008.

AMORIM, T. N. G. F.; SILVA, L. B.. Gestão estratégica de pessoas e inovação: uma parceria essencial. Revista Eletrônica: RAUnP, Natal, v.4, n.1, p.33-42, 2012.

AZEVEDO, D.; WALBER, A.L.; SCHUJMANN, A.; GARAY, A. B. S.. Representações Sociais de RH: um estudo exploratório com alunos de graduação. In: Organizações \& Sociedade, Salvador, v.19, n.60, p.51-66, 2012.

BALCEIRO, R. B.; ÁVILA, G. M.. A gestão de pessoas para o profissional do conhecimento. In: CONGRESSO BRASILEIRO DE GESTÃO DO CONHECIMENTO. Anais. São Paulo: KMBrasil, 2003.

BECKER, B. E.; HUSELID, M. A.; ULRICH, D.. Gestão Estratégica de Pessoas com Scorecard. 10 ed. Rio de Janeiro: Campus: 2001.

BIRK, G.. Governança corporativa: geração de valor: um estudo das empresas brasileiras de capital aberto com ações negociadas na Bolsa de Valores de São Paulo no período 2000 até 2011. Dissertação (Mestrado em Economia do Desenvolvimento) - Pontifícia Universidade Católica do Rio Grande do Sul, Porto Alegre, 2012.

CALDERÓN, J. A.; MOUSALLI, G. M.. Capital humano: elemento de diferenciacion entre las organizaciones. Actualidad Contable Faces, v.15, p.15-24, 2012.
CELLARD, A.. A análise documental. In: POUPART, J.. A pesquisa qualitativa: enfoques epistemológicos e metodológicos. Petrópolis: Vozes, 2008.

CÉSAR, A. M. R. V.; CODA, R.; GARCIA, M. N.. Um novo RH? Avaliando a atuação e o papel da área de $\mathrm{RH}$ em organizações brasileiras. FACEF Pesquisa, v.9, n.2, p.151165, 2006.

CHADWICK, C.. Toward a more comprehensive model of firms human capital rents. Academy of Management Review, v.42, n.3, p.499-519, 2017.

CVM. Comissão de Valores Mobiliários. Cartilha de Boas Práticas de Governança Corporativa. Rio de Janeiro, 2002.

CRESWELL, J. W.. Projeto de pesquisa: métodos qualitativo, quantitativo e misto. 3 ed. Porto Alegre: Artmed, 2010.

DEMO, G.; FOGAÇA, N.; NUNES, I.; EDREI, L.; FRANCISCHETO, L.. Políticas de gestão de pessoas no novo milênio: cenário dos estudos publicados nos periódicos da área de administração entre 2000 e 2010. Revista de Administração Mackenzie, São Paulo, v.12, n.5, p.15-42, 2011.

DOLPHIN, R. R.. Corporate reputation: a value creating strategy. Corporate Governance, v.4, n.3, p.77-92, 2004. 
ECCLES, R. G.; KRZUS, M. P.. Relatório único: divulgação integrada para uma estratégia sustentável. São Paulo: Saint Paul, 2011.

FERREIRA, A.; PEREIRA, P. M.; TEODORO, P.; THIELMANN, R.. $O$ Desafio da Gestão de Pessoas em uma Empresa de Pequeno Porte. In: SIMPÓSIO DE EXCELÊNCIA EM GESTÃO E TECNOLOGIA, 6. Anais. Resende: AEDB, 2009.

FOMBRUM, C. F.; RIEL, C. B. M. V.. Fame and Fortune: how successful companies build winning reputations. New York: Prenticde Hall, 2004.

GODOY, A. S.. Entendendo a pesquisa científica. In: HANASHIRO, D. M.. Gestão do fator humano: uma visão baseada em stakeholders. São Paulo: Saraiva, 2007.

GREER, C. R.; LUSCH, R. F. HITT, M. A.. A servisse perspective for human capital resources: a critical base for strategy implementation. Academy of Management Perspectives, v.31, n.2, p.137-158, 2017.

HITT, M. A.; IRELAND, R. D.. The essence of strategic leadership: Managing human and social capital. Journal of Leadership \& Organizational Studies, v.9, p.3-14, 2002.

IBGC. Instituto Brasileiro de Governança Corporativa. Código das Melhores Práticas de Governança Corporativa. 4 ed. São Paulo: IBGC, 2009.

IIRC. International Integrated Reporting Council. Framework do Relato Integrado. Londres: IIRC, 2013.
NARDI, P. C. C.; NAKAO, S. H.. Impacto da entrada nos níveis diferenciados de Governança Corporativa sobre a imagem institucional das empresas. Revista Contabilidade Vista e Revista, Belo Horizonte, v.19, n.2, p.85-111, 2008.

PEREZ JUNIOR, J. H.; OLIVIERI NETO, R.; SILVA, C. A. S.. Relatório Integrado. São Paulo: Atlas, 2014.

RIBEIRO, A. L.. Gestão de Pessoas. São Paulo: Saraiva, 2006.

ROSSETTI, J. P.; ANDRADE, A.. 7 ed. Governança corporativa: fundamentos, desenvolvimento e tendências. São Paulo: Atlas, 2014.

TACHIZAWA, T.; FERREIRA, V. C. P.; FORTUNA, A. A. M.. Gestão com Pessoas: uma abordagem aplicada às estratégias de negócios. Rio de Janeiro: FGV, 2001

TRIVIÑOS, A. N. S. Introdução à pesquisa em ciências sociais: a pesquisa qualitativa em educação. São Paulo: Atlas, 2008.

VERGARA, S. C.. Projetos e relatórios de pesquisa em Administração. São Paulo: Atlas, 2004.

VOMBERG, A.; HOMBURG, C.; BORNEMANN, T.. Talented people and strong brands: The contribution of human capital and brand equity to firm value. Strategic Management Journal, v.30, p.2122-2131, 2015. 